\title{
Acceptance of the 1995 John Howland Award
}

\author{
FLOYD W. DENNY, $\mathrm{J}_{\mathrm{R}}$
}

Division of Community Pediatrics, University of North Carolina, Chapel Hill, North Carolina 27599-7225

Thank you very much, Jud, for those kind remarks.

Dr. Scriver and friends, I want to express my sincerest appreciation to the officers, the council, and the members of the American Pediatric Society for bestowing on me the Howland Award. This is by far the most important and prestigious professional honor to come to me, and I am very grateful to all of you who made it possible.

I thought long and hard about what else I could or should say at this time, in addition to expressing my appreciation for this honor. My first thought was to tell you some of the exciting things that are going on with the streptococcus and rheumatic fever. Putting this aside, I then turned to my great concern

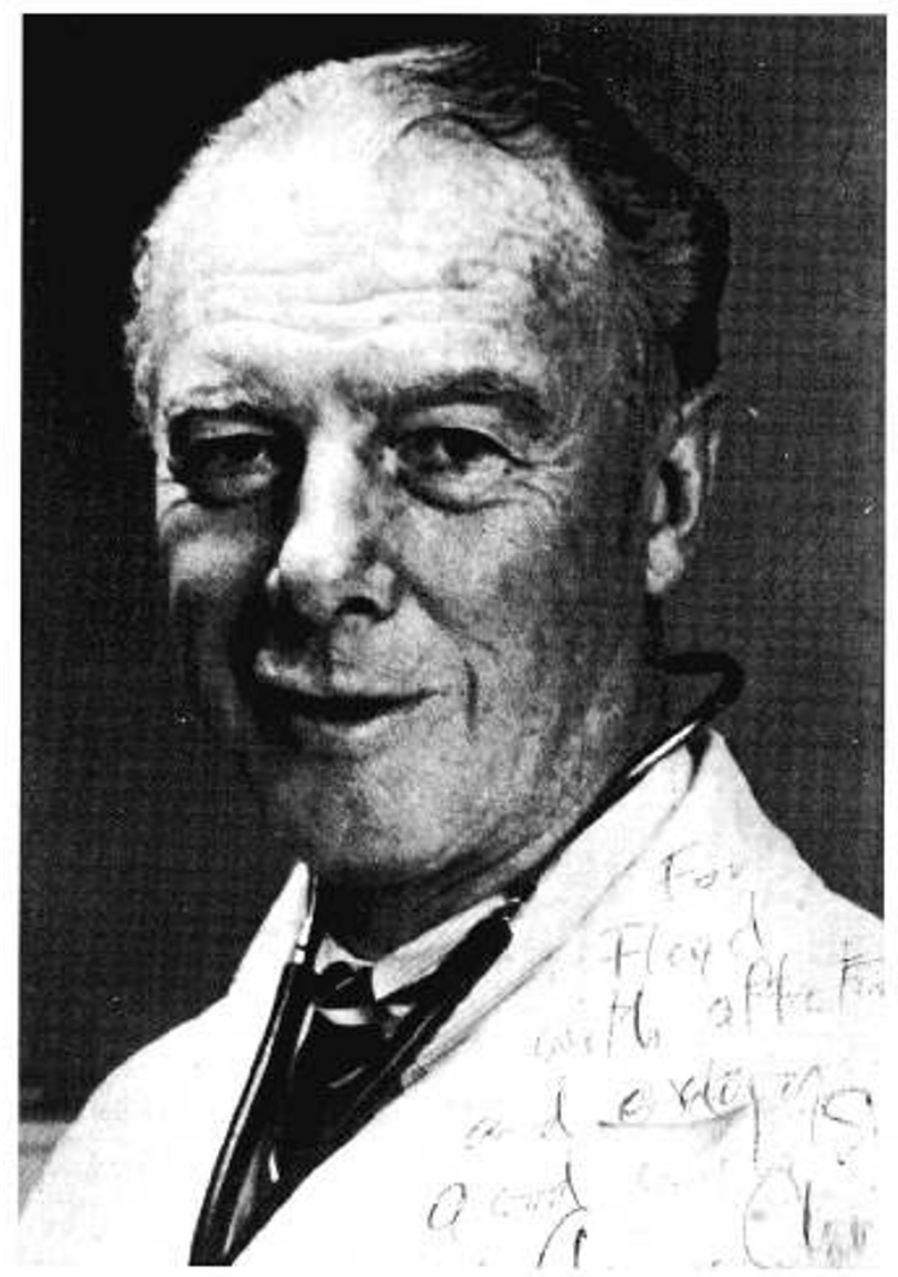

Figure 1. Amos Christie, M.D. (From: Denny, FW Infectious diseases in the last 100 years in the American Pediatric Society. Pediatr Res 1990;27: S49-S54.) about what is taking place in academic pediatrics and the clinical care of children. I despair at times of the problems faced by young scientists today; these are certainly not the halcyon days experienced by academicians of my generation. I also despair at the glacial slowness of our progress in attaining adequate care for all children.

I finally decided that none of these was very appropriate for me on this special occasion. I want instead to pay tribute to those individuals who have been my mentors, my advisors, and my collaborators over the years, who did so much for me along the way and without whom I would not be here today.

My interest in and dedication to pediatrics is due primarily to Dr. Amos Christie (Fig. 1) under whom I was a student, a resident, and a junior faculty member. He was probably the greatest teacher of pediatrics I have ever known and a fantastic

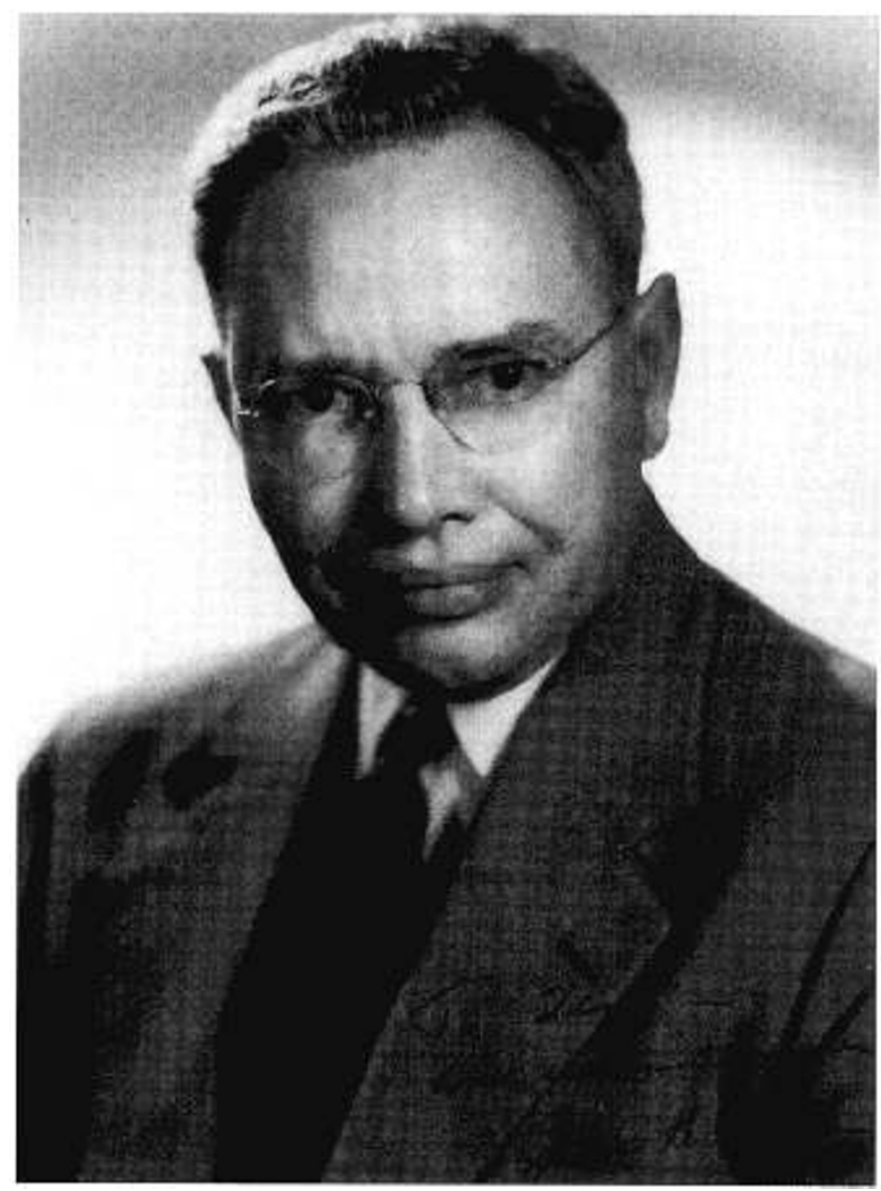

Figure 2. John H. Dingle, M.D. 


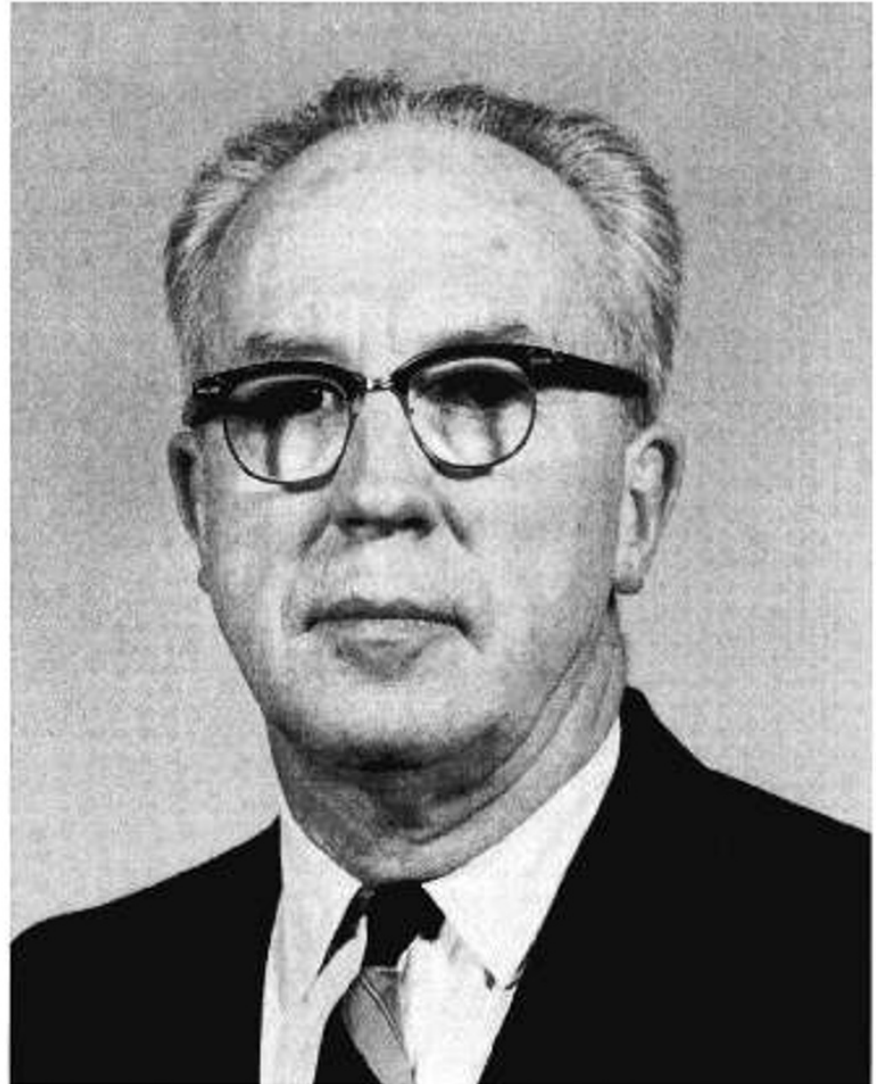

Figure 3. Charles H. Rammelkamp, Jr., M.D. (From: Denny FW Jr A 45 year perspective on the streptococcus and rheumatic fever: The Edward $\mathrm{H}$. Kass lecture in infectious disease history. Clin Inf Dis 1994;19:1110-1122. With permission from the University of Chicago Press.)

salesman for pediatrics. He was truly my pediatric "father figure" and my counselor until his death.

The next important person whom I want to recognize is Dr. John Dingle (Fig. 2), Chairman of the Department of Preventive Medicine at Western Reserve University and a prominent figure in military medicine during and after World War II. For reasons still unknown to me the Army assigned me to his department to be a member of a team to study streptococcal infections and rheumatic fever in the military. John guided me through quite a number of years, and on one occasion made it possible for me to continue a research career. I am still ever so grateful to him for all he did for me.

The head of our research team in the military was Dr. Charles Rammelkamp (Fig. 3), my research mentor and counselor during those important formative years of my career. He was the most imaginative, most generous, and most hard working scientist I have ever known. If Dr. Christie was my "pediatric father," Rammel was my "research father." The other member of our team that I want to recognize is Lewis Wannamaker (Fig. 4), a fellow South Carolinian. We grew up together in Rammel's laboratory and as Lewis once wrote: "we cut our eye teeth on the streptococcus." Lewis was my closest friend and my confidant for 35 years; incidentally, he was probably the world's greatest "streptococcologist" until his untimely death in 1983.

This brings me to my time at the University of North Carolina. Dr. Reece Berryhill (Fig. 5), the Dean at UNC,

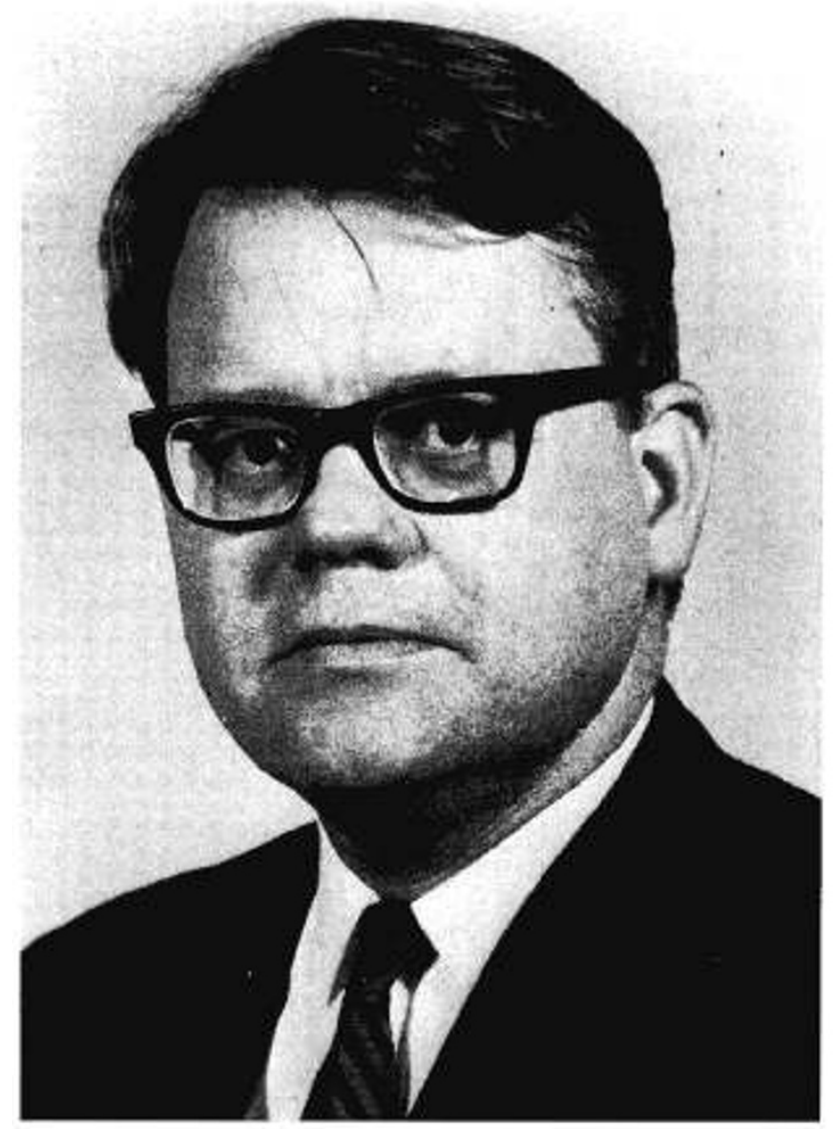

Figure 4. Lewis W. Wannamaker, M.D. (From: Denny FW Jr A 45-year perspective on the streptococcus and rheumatic fever: The Edward H. Kass lecture in infectious disease history. Clin Inf Dis 1994;19:1110-1122. With permission from the University of Chicago Press.)

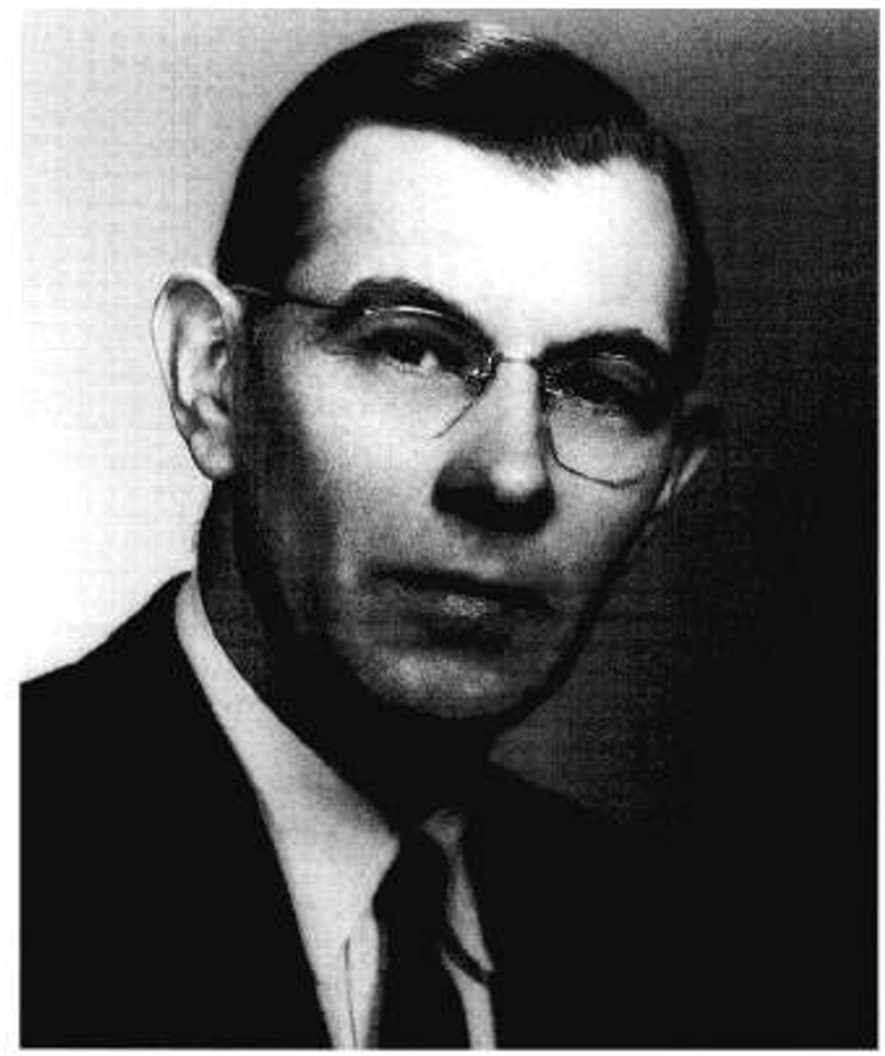

Figure 5. W. Reece Berryhill, M.D. 


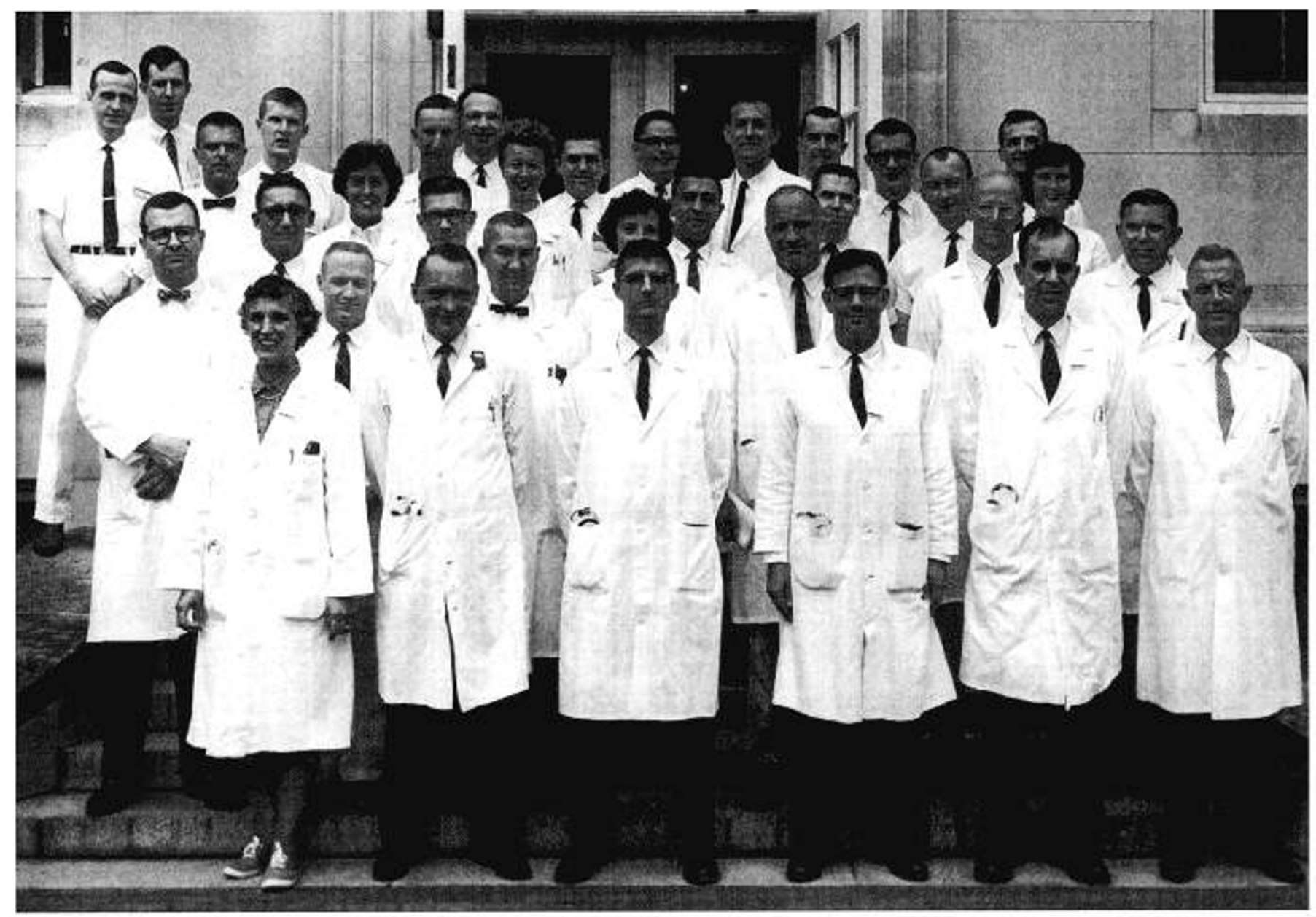

Figure 6. The 1962-1963 University of North Carolina pediatric faculty and house staff. Note: Dr. Judson Van Wyk, first row, second from left; Dr. Herbert Harned, first row, fourth from left; Dr. Harrie Chamberlin, first row, fifth from left; and Dr. Wallace Clyde, second row, far right.

brought me there and made possible what I did as a Chairman. He was the most principled man I have ever known.

The housestaff and faculty of our small department in the early 1960s are shown in Figure 6. I want to use this photograph to pay tribute to two groups and to four special individuals. First, the house staff-they were my pride and joy over the years and probably gave me more satisfaction than any other single component of the department. I also want to recognize the tremendous part played by all of the faculty of our department; each of these contributed a special part to the department's success.

At the risk of leaving out very important faculty members I want to recognize four who played special roles in the department: Dr. Judson Van Wyk, Dr. Herbert Harned, Dr. Harrie Chamberlin, and Dr. Wallace Clyde (Fig. 6). The first three were in the department when I arrived in Chapel Hill and have remained there until this day; they formed the backbone of our growing department. All three developed into national and international figures in pediatrics - Van Wyk in endocrinology, Chamberlin in child de- velopment, and Harned in cardiology. The success of our department rested clearly on their shoulders - and they delivered.

Wallace Clyde was a fellow with me at Western Reserve and joined me shortly after my arrival at the University of North Carolina. He made it possible for me to continue my interests and involvement in research in respiratory infections; and I am very grateful to him for this. He, too, developed into an international authority in respiratory infections, especially those due to mycoplasmas.

I want to recognize especially the role played by my family: my children-Zoe, Mark, and Tim, and my wife-Barbara. Without their love and support none of what I accomplished would have been possible. With it this has been a glorious and very satisfying experience.

Finally, I want to pay tribute to the American Pediatric Society. Working in the APS has given me much pleasure over the years, and my association with its activities have always been enjoyable and stimulating.

Thank you again for bestowing on me this great honor. 